\section{A theory of goal attainment (King 1981) and ambulatory care oncology nursing: An introduction}

\section{by Heather B. Porter}

\section{Abstract}

Clear theoretical guidance can assist oncology nurses to deliver high quality care to cancer patients in outpatient settings. Theory-based nursing can also help practitioners explain their activities with cancer patients in an onganized and objective manner, so that others may understand and appreciate the complexities of ambulatory oncology nursing. The puopose of this paper is to examine the theory of goal attainment in A Theory for Nursing by Imogene King (1981) for its usefulness as a guide for the practice of ambulatory oncology nursing. The framework for this nusing theory is outlined, King's (1981) theory of goal attainment with its concepts is described, and its relationship to ambulatory care shown. The fit of a theory of goal attainment with ambulatory oncology nursing is illustrated by examples from a typical oncology outpatient clinic in a large urban hospital.

\section{A theory of goal attainment and ambulatory care oncology nursing}

Ambulatory care is defined as the arena of health care that provides access to the general health care system. In its widest sense, it incorporates all domains where an individual receives health services and then returns to the community. Ambulatory care nurses have been viewed along a continuum from task-oriented assembly line workers who process a designated number of patients in a series of 15-minute appointments, through to the vision of nurses as collaborative partners with physicians and other health professionals in the delivery of comprehensive health care. (Howard \& Pajor, 1987; Koerner, 1987).

In recent years, the focus of modern health care has been shifting rapidly from the hospital to the ambulatory care setting chiefly due to continuing economic restraints. As well, there has been an accompanying shift toward the enlargement of nursing roles in this setting. Ambulatory care nursing responsibilities now include assessment, case management of patients with acute and chronic illnesses, delivery of complex treatments and procedures on an outpatient basis, patient counselling and education, and primary care (Hastings \& Muir-Nash, 1989).

Clear theoretical guidance can assist oncology nurses to deliver high quality care to cancer patients in outpatient settings. Theory-based nursing can also help its practitioners explain their activities with cancer patients in an organized and objective manner, so that others may understand and appreciate the complexities of ambulatory oncology nursing.

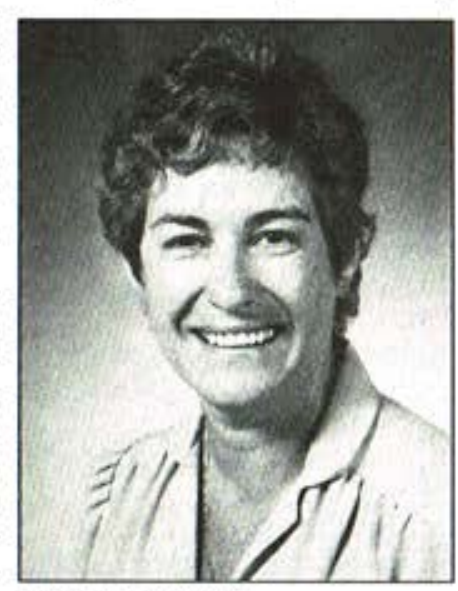

Heather B. Porter
If any theory is to be really serviceable, however, it must enable concerned individuals to understand the problems of here-and-now situations and must provide assistance when a course of action is needed. The purpose of this paper is to examine the theory of goal attainment in A Theory for Nursing by Imogene King (1981) from the perspective of its usefulness as a guide for the practice of ambulatory oncology nursing. The framework for this nursing theory will first be outlined, then a theory of goal attainment with its concepts will be described, and its relationship to ambulatory care will be shown: The fit of this theory (King, 1981) with ambulatory oncology nursing will be illustrated by examples from a typical oncology outpatient clinic in a large urban hospital.

\section{A theory for nursing}

A nursing theory is a set of interrelated concepts or elements that prescribe a systematic view about phenomena for the purpose of guiding nursing research and practice. A conoept is simply a label given to an idea which may be either concrete or abstract in nature. Concepts are the building block of theory and nursing phenomena are the realization of nursing concepts (Hardy, 1974; Walker \& Avant, 1988)

In ATheory for Nursing, the author, Imogene King(1981), presents three dynamic interacting systems as an open framework for nursing. These consist of the personal system, the interpersonal system, and the social system. In King's (1981) theory it is understood that personal systems refer toindividuals, for example, a nurse and a client are each separate personal systems; interpersonal systems consist of two or more individuals interacting in a relationship such as a nurse and a cancer client and family; and that social systems are large groups with common interests and goals, such as ambulatory care centres or the Canadian health care system. The goal for nursing in this systemic framework is helping people achieve and maintain their health.

King (1981) places the personal system at the centre of her conceptual framework (Figure One). An individual client and nurse are each a total system. Concepts within this system include perception, each person's representation of reality, an awareness of people and things; growth and development, those continuous changes in biological and behavioural levels of activities; time, the sequence of events moving into the future; and space, the physical area called territory.

The interpersonal system surrounds the personal system in King's (1981) model and refers to twoor more individuals in a relationship with one another and interacting towarda common goal or interest. Concepts within thissystem

\section{UNE THÉORIE DE L'ATTEINTE DES OBJECTIFS (KING, 1981) ET LES SOINS INFIRMIERS ONCOLOGIQUES AMBULATOIRES ABRÉGÉ}

Des guides theoriques clairs aident les infirmières à donner des soins de haute qualité lors de leurs consultations externesaux patients souffrant du cancer. Les soins infirmiers basés sur la théorie aident aussi les praticiennes à expliquer, de façon objective et organisée, les activités qu'elles suivent avec leurs patients du cancer, de telle sorte que les autres professionnels puissent comprendre et apprécier la complexité des soins infirmiers oncologiques ambulatoires. L'article examine la theorie de l'atteinte des objectifs "A Theory For Nursing" présentée par Imogene King (1981) et l'utilité qu'elle pourrait avoir pour guider la pratique des soins infirmiers oncologiques ambulatoires. Larticle souligne le cadre de cette théorie des soins infirmiers, décrit la théorie de King (1981) sur l'atteinte des objectifs et montre les liens qui existent entre elle et les soins ambulatoires. Une théorie de l'atteinte des objectifs cadre bien avec les soins infirmiers oncologiques ambulatoireset l'article illustre ce fait a l'aide d'exemples tirés d'un service d'oncologie typique dispensant des consultations externes en ville, dans un grand établissement hospitalier.

Heather Porter is a Maurice Legault Fellow - Canadian Cancer Society. Currently she is a doctoral student at University of California in San Francisco where she is completing a DNSc. 
are interaction, the process of perception and communication between person and environment and/or between individuals represented by goaldirected verbal and non-verbal behaviours; communication, an information sharing process consisting of verbal and non-verbal elements and incorporating signs and symbols; role, a set of behaviours expected of an individual occupying a pasition in the social system; stress, a dynamic state between person and the environment for the maintenance of growth, development and performance; and transactions which are observable behaviours of humans interacting with their environment. Transactions lead to goal attainment, effective health care, and enhanced growth and development which are the outcomes of using this nursing theory (King, 1981, 1988).

The social system encompasses both the personal and the interpersonal systems in King's framework. This means that the relationships of the individual groups may be set within a common culture or belief. These subsystems may be families or religious, educational, or work groups. Concepts included in this system are authority which guides, directs, and influences behaviour in any organization; power defined as the ability and the will to affect others' performance and to control events and behaviours; and decision-making which is concerned with making a choice of a plan of action to meet a goal in a systematic way following an analysis of the facts (King, 1981; Robbins, 1987).

Ambulatory oncology nurses engage in decision-making in the natural course of their professional practice with cancer patients and families and can acquire the authority and power of the expert in cancer nursing care through education and experience.

\section{A theory of goal attainment}

A theory of goal attainment has been derived from a systems framework. Although personal and social systems significantlyaffect the quality of nursing care, the major elements in this theory are within interpersonal systems. The patient and the nurse meet within a health care organization to establish mutually agreable health care goals for the patient, and to discover and agree on means to attain these goals. Movement toward goal attainment begins with the nurse's assessment of the patient's problems and health concerns, the patient's perception of these same disturbances, and a mutual sharing of information related to the problems requiring solutions. Together, the nurse and patient then consider ways to solve the identified problems and agree on the actions necessary from each person to achieve their goal of problem solution. Interactions and transactions then occur between these two persons until the problem is solved (goal attainment) (King, 1981, 1988).

\section{Application to ambulatory oncology nursing}

A theory of goal attainment is particularly applicable to ambulatory oncology nursing since King (1981) regards a person mainly as a social being and requires that the patient be conscious and capable of interaction and communication with the nurse if goals are to be attained. Furthermore, the patient and the nurse are viewed as equal partners in the nursing process, a process in which the nurse's action depends on the client's active participation.

Figure One: A Conceptual
Framework For
Nursing Dynamic
Interacting Systems
Used with permission from
King, I.M. (I981),
A Theory for Nursing.
New York: John Wiley \& Sons. P. I1.

This assumption is also at the heart of the practice of ambulatory oncology nursing (Buchanan, 1987).

Significantly, King (1981) specifically infers the applicability of her theory of goal attainment to the ambulatory care setting, "Nurses who function in ambulatory care settings observe and measure health states of people with chronic disease such as diabetes, and through mutual goal-setting help individuals maintain a functional state of health and prevent complications" (King, 1981, p.2).

For example, in the ambulatory health care model, cancer patients visit a clinic for assessment and treatment appointments and then return home to look after themselves between visits. Therefore to achieve a goal of successful health management at home, especially if they are undergoing treatment, requires that patients learn about their disease, therapy, and necessary self management while at the clinic. Such patient education, as well as ongoing patient support, is a central responsibility of the ambulatory oncology nurse today, so that the mutual goal of a knowledgeable cancer patient capable of self-management while using available health care resources as needed is attained.

Finally, King's (1981) goal attainment theory is easily implemented in the ambulatory care setting and provides a framework that is adaptable enough for nurses to readily see that their current practice has a base in theory (Austin \& Champion, 1983; Byrne \& Schreiber, 1989; Frey, 1989; Hanucharumkul, 1989; Husband, 1988; Department of Nursing, London Regional Cancer Centre, Personal Communication, September 4, 1990).

\section{Illustration}

The theory of goal attainment is positioned chiefly in the interpersonal system described by King (1981). Major concepts in this system are human interaction, communication, and transaction. These were clearly illustrated in one nurse/patient dyad observed.by the author at an urban oncology outpatient clinic. The nurse, Tracey, is an oncology nurse with seven years experience. The patient, David, has AIDS-related lymphomawhich was being treated with intravenous chemotherapy every three weeks. David has been attending the clinic for care and treatment of his cancer for some months. $\mathrm{He}$ was referred to Tracey soon after his first visit because his anxiety level was appreciably higher than most patients. He was terrified of receiving chemotherapy because of the injection itself and because of the severe nausea and womiting he experienced after each treatment.

It was clear from their comments that Tracey and David admired and respected one another. David told the author that Tracey's technical expertise and her telephone call to him after each clinic session had enabled him to continue his treatment though he still dreaded every visit. Tracey remarked that through their ongoing communication they had discovered mutual acquaintances and shared an interest in commercial art. She said that discussion on both these topics during treatment sessions achieved their ongoing mutual goal of calmness and a sense of control for David.

Concept of human interaction. To each interaction the persons involved bring their individual perceptions and interpretations of the meaning of pertinent information, and make decisions and judgments on that data based on their life experiences. Therefore some mental action and reaction naturally occurs preparatory to engaging in an interaction that will lead to a transaction or the realization of a goal (King, 1981, 1988).

The author observed that Nurse Tracey perceived David as a client rather than a patient with little of the dependency that the latter term implies. She saw him as an active participant in the health care for which he had contracted rather than simply a recipient of health services. This equal partnership in care was observed when Tracey asked for David's treatment preferences regarding the day and time he though best. She also read with interest a recent article he brought for her on management ideas for AIDS patients and remarked how helpful they could be to her nursing practice.

David stated to the author that for him, Tracey was the one constant, competent health care provider in the clinic. He illustrated his comment by explaining that when he was admitted recently to a hospital on the other side of the city, Tracey advocated for him by telephoning the nursing unit toexplain to the staff how to care for him. David called Tracey his "lifeline".

Concept of communication. Communication can be described as an information exchange which has both verbal and nonverbal aspects to it(King, 1981). 
Tracey and David demonstrated skilful use of verbal and nonverbal communication. They shared a warm and casual kind of verbal exchange interlaced with reminiscences and humorous anecdotes. The use of touch, so natural to this very perceptive nurse, was not employed to communicate with this individual. Tracey explained to this observer that David was really a very private person and was uncomfortable being touched, except for examination or treatment. However, the depth of understanding between these two persons was obvious in the warmth of their facial expressions.

Concept of transactions. "Transactions are a process of interaction in which human beings communicate with the environment toachieve goals that are valued" (King, 1981,p. 82). Transactions lead to goal attainment, effective health care, and enhanoed growth and development.

The functional elements of the concept of transaction are illustrated in Figure Two and are demonstrated in the example of the process of goal attainment. These include action (A-1) which is when one member of the nurse/patient dyad initiates behaviour, and reaction $(\mathbf{R})$ is seen when the opposite member of the dyad responds with behaviour. A disturbance or problem $(\mathbf{P})$ is then stated or perceived by one or both dyad members and a goal is mutually set (MGS). Exploration of means (E) to achieve the goal is made and/or agreed to by both parties (A-2) and the transaction (T) occurs until the goal is attained (GN) (Austin \& Champion, 1983; King, 1981). In the example of a transaction in an outpatient oncology clinic, the elements of this concept are highlighted by the capital letter assigned to each functional element.

\section{Example of the process of goal attainment}

(A-1) At nine o'clock one clinic morning Tracey received a telephone call from her client David saying, (P) "The commute is terrible so I'll have to come in much earlier than my appointment time and I want to leave again right away so I can get home before I get sick. I'll have my blood taken on the way in. Is this okay?" (R) Tracey responded quickly, "We'll be waiting for you, drive safely!"

Tracey's short comment indicated her understanding of the problem $(\mathrm{P})$, her acceptance of the goal of an earlier appointment and an immediate treatment (MGS), and her agreement with David's suggestion that he have his blood taken in the laboratory on his arrival and wait for the results before coming to the clinic (E and A-2). "We'll be waiting" meant that the means to achieve the goal on Tracey's part would be explored and arrangements made prior to his arrival (E) to facilitate the prompt administration of his chemotherapy (MGS). All these elements so necessary to the attainment of a mutually acceptable goal by nurse and patient were accomplished with very little actual communication, just a few sentences on the telephone. This was possible because Tracey and David had been working together to manage his cancer-related health care for several months and had learned to understand one another.

After the telephone call, Tracey marshalled her resources (E). Directions were given to the admitting clerk that when he appeared, David was to be
Figure Two: Classification System of Nurse-Patient Interaction That Leads to Transactions

Elements in Interactions:
(A-1) Action
(D) Disturbance
(E) Explore means
to achieve goal
(R) Reaction
(MGS) Mutual goal setting
(A-2) Agree on means to achieve goal
(T-GA) Transaction - goal achieved

Used with permission from King, I.M. (1981), A Theory for Nursing New York: John Wiley \& Sons. P. 156.

escorted immediately to the chemotherapyroom where Tracey, the only clinic nurse he trusted with this procedure, would start the intravenous infusion. The assigned physician was asked to conduct David's examination in the chemotherapy room the moment the client was settled in bed. At Tracey's request a selection of the appropriate intravenous medications was premixed in fluid by the chemotherapy nurse awaiting the doctor's treatment prescription for David.

David performed his part in meeting the goal of a prompt and successful treatment when he arrived waving his completed blood report and he did not lose his temper when Tracey was a few minutes late arriving at his side to insert the intravenous line. Also he suggested a possible site for the line and tried very hard to control his customary agitation about the IV procedure by draping a towel over his face so Tracey would not be distracted by his facial grimaces $(\mathrm{T})$.

The goal of this transaction was met with triumphant success! - The IV was established at the first attempt (Tracey was so relieved!), David's blood levels were quite adequate for a complete treatment, and he was in and out of the clinic in the record time of two hours (T-GA).

Such mutual goal-setting and attainment occurs frequently today in ambulatory care settings as cancer patients strive for independence and control ower their lives with this chronic disease with the assistance of their health care providers. Recognizing that most persons are naturally goaldirected can assist the oncology nurse to plan with patients tomeet their needs and objectives using as guidance the functional elements described in King's (1981) theory of goal attainment.

In summary, it has been shown that A Theory for Nursing by Imogene King (1981) is a very realistic framework for ambulatory cancer nursing care and that her theory of goal attainment has distinct application to the practice of oncology nursing in ambulatory care settings. With this theory to provide direction, oncology nurses can not only be supported in daily professional activities, but can explain this nursing role to others so that full understanding of the complexities of this nursing speciality and its value to cancer patients can be promoted.

\section{References}

1. Austin, J. \& Champion, V. King's theory for nursing explication and evaluation. In P.L. Chinn (Ed.), Advances in nursing theory development, Rockville, MD: Aspen, 1983, 49-61.

2. Buchanan, B.F. Conceptual models: An assessment framework. Journal of Nursing Administration, 17, (10), 1987, 22-26.

3. Byrne, E. \& Schreiber, R. Conceptual framework at the bedside. Journal of Nursing Administration, 19, (2), 1989, 28-32.

4. Byrne-Coker, E.\& Schreiber, R. Kingat the bedside. The Canadian Nurse, 1990, January, 21-26.

5. Frey, M.A. Social support and health: A theoretical formulation derived from King's conceptual framework. Nursing Science Quarterly, 2, (3), 1989, 138-172.

6. Hanucharurnkul, S. Comparative analysis of Orem's and King's theories. Journal of Advanced Nursing, 14, (5), 365-372.

7. Hardy, M. Theories: Components, development, and evaluation. Nursing Research, 23, (2), 1974, 100-106.

8. Hastings, C. \& Muir-Nash, J. Validation of a taxonomy of ambulatory nursing practice. Nursing Economics, 7, (3), 1989, 142-149.

9. Howard, D.M. \& Pajor, M. Ambulatory care administrators, whoare they? Journal of Ambulatory Care Management, 10, (1), 1987, $70-77$.

10. Husband, A. Application of King's theory of nursing to the care of the adult with diabetes. Journal of Advanced Nursing, 13, (4), 1988, 484-488.

11. King, I.M. A Theory for Nursing. New York, NY: Wilcy, 1981.

12. King, I.M. Keynote address: Translating research into practice. Journal of Neuroscience Nursing, 19, (1), 1987, 44-48.

13. King, I.M. Concepts: Essential elements of theories. Nursing Science Quarterly, 1, 1988, 22-25.

14. Koerner, B.L. Clarifying the role of nursing in ambulatory care. Journal of Ambulatory Care Management, 10, (3), 1987, 1-7.

15. Robbins, S.P. Organization theory, structure, design, and applications. Englewood Cliffs, NJ: Prentice-Hall Inc., 1987.

16. Walker, LO., \& Avant, K.C. Strategies for theory construction in nursing. (2nd ed.), Norwalk, CT: Appleton \& Lange, 1988. 